\title{
Analysis of the possibilities of geometry of the Rosia Poieni mining field
}

\author{
Dorel Gusat ${ }^{1 *}$, Ioan Bud ${ }^{1}$, and Mircea Goia $^{2}$ \\ ${ }^{1}$ Technical University of Cluj Napoca, North University Center of Baia Mare, 62/A Victor Babes \\ Street, Baia Mare, Romania \\ ${ }^{2}$ CUPRUMIN ABRUD S.A. Open Pit Director, Piaţa Petru Dobra, nr. 1, Abrud, jud. Alba, Romania
}

\begin{abstract}
This paper is made within the European project GoldenEye Nr. 869398 Type Horizon 2020 and aims at geometrization in 3D format of the Rosia Poieni deposit. This geometrization will be based on the information on the contents of the deposit, the economic analysis, and the calculations of the stability of the open pit and the adjacent industrial waste dumps. The analysis of data from the literature on content is in a very wide and insufficiently relevant range. The study will be based on the latest scanning technologies, AI, numerical simulations (FLAC 2D), which will form the basis of an economic analysis and forecast of metal prices in the future in order to identify exploitable limits both horizontally and vertically. Depending on the extension of the exploitation area and the definition of the deep exploitation limit by up-to-date exploitation, stability calculations will be performed, which will finally allow the geometry and safety of the deposit. Also, this geometrization will allow the decision-making of exploitation, extension, optimization by the management team and the administrative council of CUPRUMIN ABRUD S.A.
\end{abstract}

\section{Introduction}

Within the European Union project GoldenEye Nr. 869398 Type Horizon 2020 the GoldenEye project will implement a number of operation applications targeting mineral detection, operational efficiency, safety and environmental monitoring.

Goldeneye will execute various activity applications focusing on mineral location, operational proficiency, wellbeing and ecological observing. Wellbeing applications will incorporate the observing of slope and benches stability (for open pit mines), rock security (for underground mines), filter cushion solidness just as the uprightness of surface offices and access streets.

Different applications will incorporate far off mineral identification to decrease required impacting, hardware and reserve following to improve gear and material streams, and so on.

A Consortium of 16 partners (3 Mining solution providers, 7 Sensor companies, 4 Mining sites, 3 Universities) across Europe are working together to create a TOOL KIT for a safer and environmental friendlier mining operations. This project is coordinated by

\footnotetext{
* Corresponding author: dorel.gusat@gmail.com
} 
TEKNOLOGIAN TUTKIMUSKESKUS VTT OY - Finland's Research Institute for a period of 3 years.

Ecological applications of the tool kit will incorporate the observing of tailings dams and the slopes steadiness of waste dumps with early notice ready frameworks to distinguish potential waste dump hazards and take actions in advance.

\section{General approaching}

The copper ore deposit from Roşia Poieni geographically is located, at $23^{\circ} 10^{\prime}$ east longitude and $46^{\circ} 20^{\prime}$ north latitude, in the area of the Apuseni Mountains, in the southern extremity of Metaliferi Mountains, about $7 \mathrm{~km}$ south of the Arieş river. Geologically, the deposit belongs to the Bucium-Roşia Montană area in the pit Bucium, in which Cretaceous (Sinonian) and Tertiary (Pliocene) formations meet on a crystalline foundation known as the "crystalline spur of Baia de Arieş" and crossed by the volcanic products of neogene magmatism $[1,2]$.

The extraction of the mining mass in the Roşia Poieni open pit is done as follows: - in benches with a height of $15 \mathrm{~m}$. - no. benches: 24; - width of the berms: 12-20 m; - final quota at the quarry: 550 a.s.l., the current quota of the quarry is $820 \mathrm{~m}$; - the today depth of the quarry: $353 \mathrm{~m}$; - methods of drilling with blasting are applied (Figures 1 and 2).

The partner CUPRUMIN holds an exploitation licence for a total industrial surfaces of $11,2109 \mathrm{~km}^{2}$.

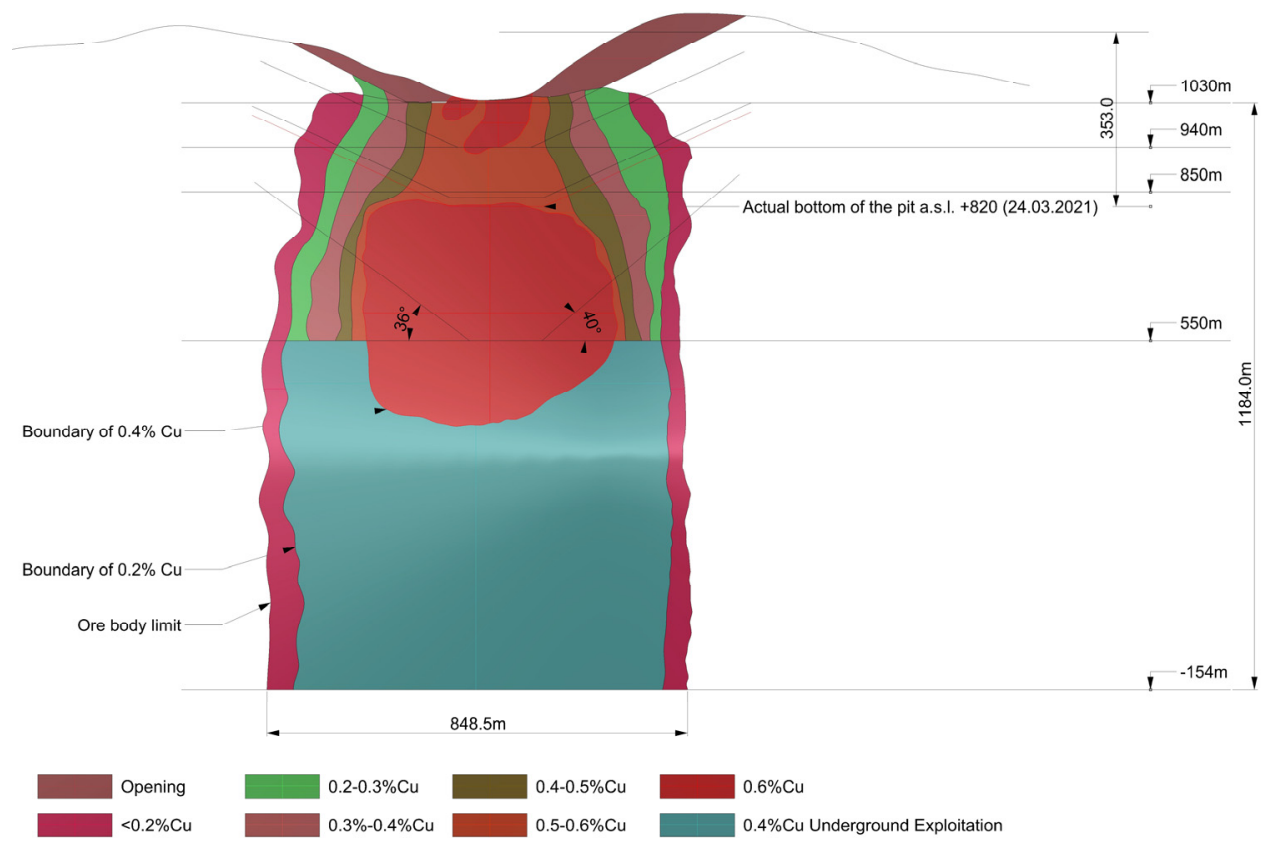

Fig. 1. Ore body of Rosia Poieni mining field, after [3].

Regarding the geomechanical parameters of the rock, a large dataset is already available for the area of the Rosia Poieni several tests have been done and the results were published already [4-6].

The aim of authors analytics in this paper is to create several batch files of calculations in FLAC 2D [7,11] to integrate the existed geometry, waste material dams, mechanical parameters and the coupling of fluid-mechanic simulations in the TOOL KIT of the 
GoldenEye Consortium. The results will be integrated in the User Platform created in the frame of the GoldenEye Project. Several analytics will be performed using the Artificial Intelligence also developed by the partners in the project.

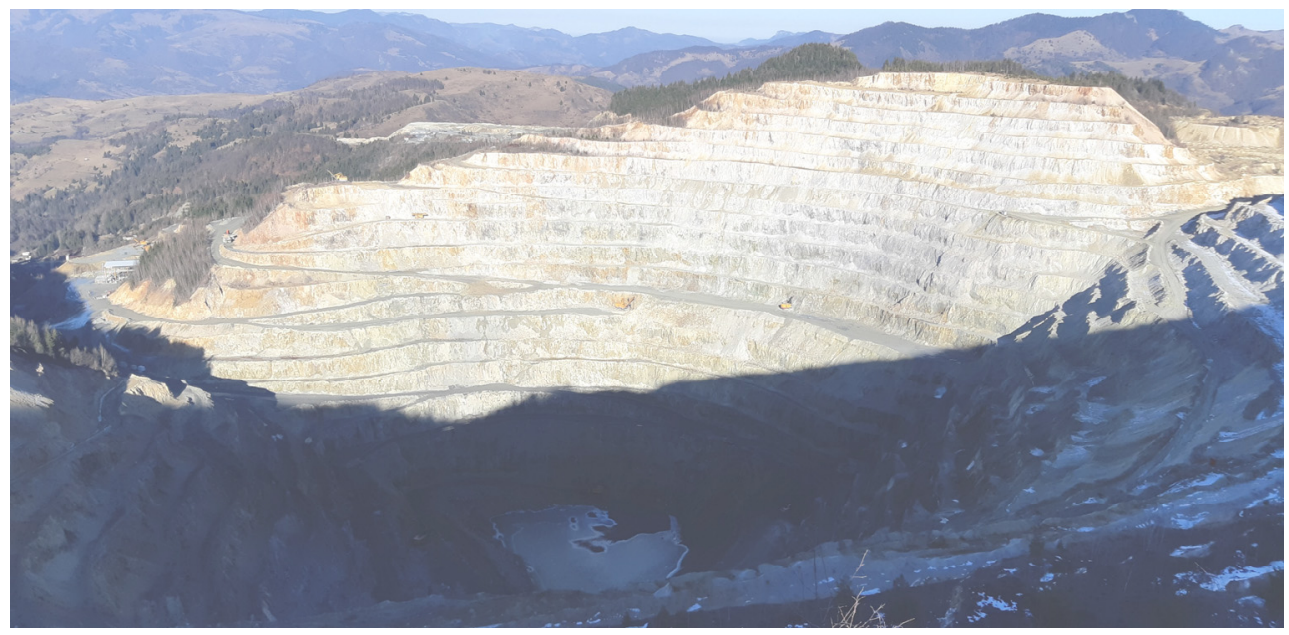

Fig. 2. Open pit Rosia Poieni mining field (Photo: 02.2021).

\section{Rock mechanical simulation of the general angle of the open pit}

As soon as the overburden is excavated, the material is removed and dumped. Modelling in $2 \mathrm{D}$ with the mechanical parameters of the rock suggest an analysis of the general open pit angle between $35^{\circ}$ and $40^{\circ}$ [3, 4, 7-10].

The 2D numerical calculations/simulations of the berms has been carried out with the software FLAC-2D. Figure 3 shows the geometry generated in FLAC-2D for a general open pit angle of $35^{\circ}$ with 24 berms and a resulted Maximum principal stress for a depth of $360 \mathrm{~m}$ around of $\sigma_{1}=8.7 \mathrm{MPa}$.

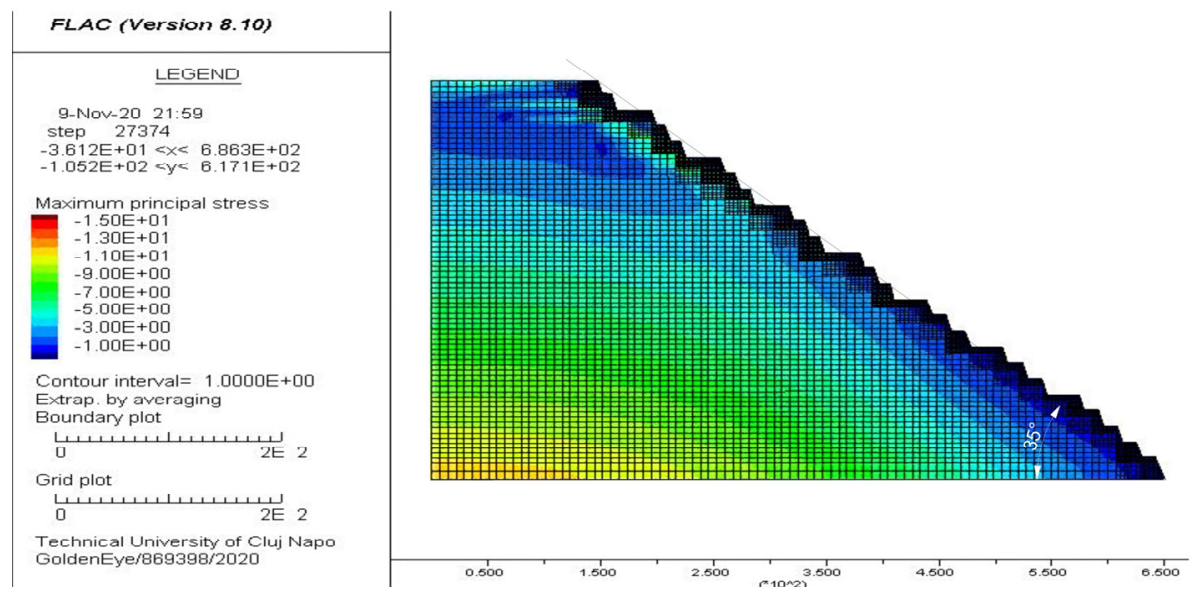

Fig. 3. Mesh generation with calculated $\sigma_{1}=8.7 \mathrm{MPa}(24$ berms $)$ 
In the rock mechanics the most important numeric methods are the finite elements method (FEM), the finite differences method (FDM), the discrete elements method (DEM) and the Boundary element method (BEM). In the present paper a FDM program (FLAC2D) for the modeling of the open pit Rosia Poieni was used.

A homogeneous and isotropic body for the continuous mechanics was assumed for the solid act.

The models are characterized by reversible deformations upon unloading; the stress strain laws are linear and path-independent [6]. The modulus of elasticity $\mathrm{E}$ has the definition as follows (Formula 1):

$$
E \cdot\left(\begin{array}{c}
\varepsilon_{x} \\
\varepsilon_{y} \\
\varepsilon_{z}
\end{array}\right)=\left(\begin{array}{l}
\sigma_{x} \\
\sigma_{y} \\
\sigma_{z}
\end{array}\right)-v \cdot\left(\begin{array}{l}
\sigma_{y}+\sigma_{z} \\
\sigma_{x}+\sigma_{z} \\
\sigma_{y}+\sigma_{x}
\end{array}\right)
$$

$\varepsilon$ is the relative length variation, $\sigma$ the stresses and $v$ the lateral elongation numeral. The modulus of elasticity has the physical unit force per area. Equation 2 and equation 3 show the $\mathrm{G}$ and the $\mathrm{K}$ is the bulk modulus. The modulus will be applied at the unit force per area.

$$
\begin{gathered}
G=\frac{E}{2 \cdot(1+v)} \\
K=\frac{E}{3 \cdot(1-2 \cdot v)}
\end{gathered}
$$

$\gamma$ is the relative variation of angle and $\delta$ is the tensile stress. The bulk modulus $\mathrm{K}$ is calculated by formula (3). It describes the relation of a tension to a variation of volume of a material, which will be exposed to an axial stress. The equations were calculated in FLAC according to the Lagrangian formulation. Internally the program with the method of the explicit finite differences applies for the calculation.

For the constitutive models the failure envelope for the modeling corresponds to a Mohr-Coulomb criterion (shear yield function) with tension cut-off (tensile yield function).

The geotechnical evaluation has been carried out with geomechanical parameters taken from [3-5]. During the project, a RMR characterisation of the rock mass will be conducted in order to apply the rock mass properties instead on laboratory results, which normally will indicate a higher values.

The used density was unsaturated. For the geomechanical simulation it was assumed that a dewatering of the open pit Rosia Poieni is completely under control. For a more precise evaluation, the influence of the water level on the stability will be analysed by adding in the system the water level. Also, the distribution of the faults and cracks will be included in the model. Therefor the Mohr-Coulomb material law, describing the elastoplastic material behaviour of the rock, can be used since the mechanical load is caused by the overburden pressure and the formation of the benching in the mining area.

The present geotechnical evaluation does not consider the additional stresses caused by the dump sites near the open pit have not been simulated. Information regarding the mass of these dumps and their position will be evaluated during this project. This can be included in future evaluations also by the Boarding Members of the CUPRUMIN ABRUD.

\section{Results and conclusions in Factor of Safety assessment}

For the generated mesh and geometry in the Figure 3 a simulation of Factor of Safety was performed using the geomechanical characteristics described in [3-5, 9]. Figure 4 indicates a $\mathrm{FoS}=2.48$ for a system of 24 berms and a general pit angle of $35^{\circ}$. 


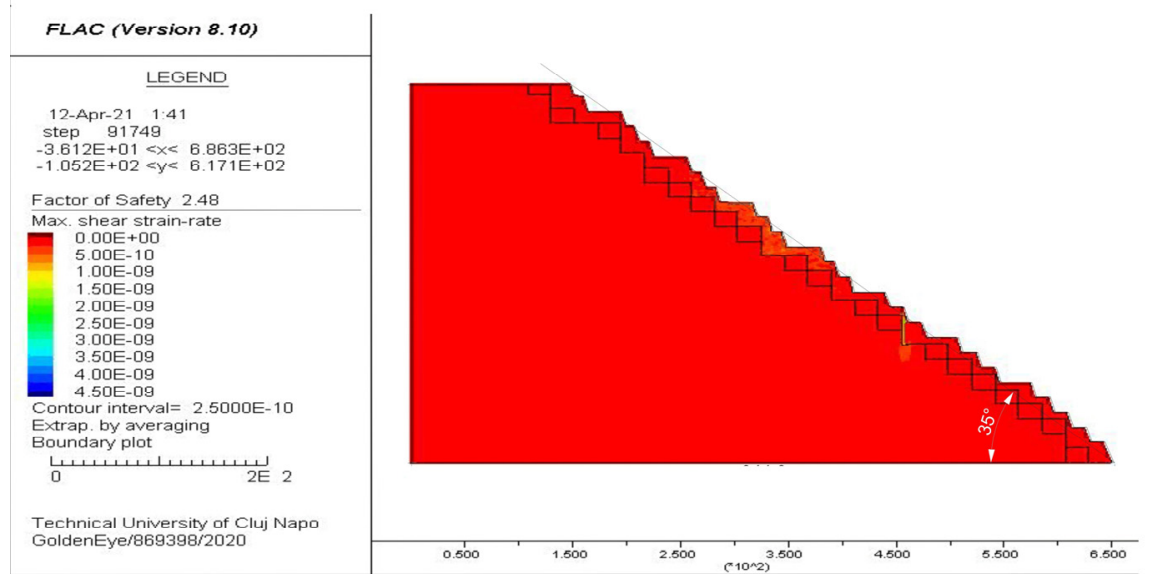

Fig. 4. $\mathrm{FoS}=2.48$ and Max. Shear strain-rate ( 24 berms)

It can be observed, that in some part of the benches, additional simulations are needed to be performed.

A wide range of meanings is applied to the words "modeling" and "simulation", depending on different disciplines. However, from the FLAC perspective of the computational way (numerical modeling / simulation) of the benches the following two definitions have been used [6].

Model: "is a simplistic reproduction of a planned or really existing system with his processes in another conceptual or concrete system...". The terminology "Model" for FLAC defines the generation and production of a real, existing and idealized system (e.g., benches).

Simulation: "is copying a system with his dynamic processes in an experimentalcapable model to reach the knowledge which is transferable on the reality". The terminology Simulation defines a dynamic change of the model (gradual solution) brings the new knowledge (changes of the primary stresses and new plastifying zones).

A development of the open pit bellow $520 \mathrm{~m}$ asl should be analyzed in detail according to new geomechanical sampling and laboratory investigations of the rock sequence (triaxial compressive tests).

These changes of the general open pit will dramatically increase the volume to be excavated and consequently the costs of overburden removal as well.

The authors would like to thank to European Union for the project GoldenEye Nr. 869398 Type Horizon 2020.

\section{References}

1. M. Sandulescu, Geotectonics of Romania (in Romanian) (Editura Tehnica, Bucharest, 1984)

2. E. Marcoux, L. Grancea, M. Lupulescu, J. P. Milesi Mineralium Deposita 37: 173-184 DOI 10.1007/s00126-001-0223-x (2002)

3. V.D. Onet, E. Cozma, I. Onica. Annals of the University of Petroşani, Mining Engineering, 13: 35-41 (2012)

4. I. Onica, E. Cozma, D. Onet. Annals of the University of Petroşani, Mining Engineering, 13: 6377 (2012)

5. V. Arad, Rock mechanics (in Romanian) (Editura Didactică şi Pedagogică, Bucureşti, 1995) 
6. Itasca Consulting Group, Inc. FLAC - Fast Lagrangian Analysis of Continua, Ver. 8.1 User's Guide. Minneapolis: Itasca. (2019)

7. M. Lazăr, F. Faur, Stability and arrangement of slopes and slides. Computation examples (in Romanian) (Editura Universitas, Petrosani, 2015)

8. A. Amodio, H. Zhou, N. Boylan, Applied Numerical Modeling in Geomechanics Billaux, Hazzard, Nelson \& Schöpfer (eds.) Paper: 11-10. (2020)

9. M. Toderas, C. Danciu. Geomechanical Assesstent Model of Rocks (Lambert Academic Publishing, 2021)

10. I. Bud, S. Duma, Rock Mechanics, (North University Edition, Baia Mare, 2007)

11. D. Gusat, I. Bud, Scientific Bulletin Series D: Mining, Mineral Processing. 34: 29-37. (2020) 